\title{
Frequency of quinolone resistance genes among extended-spectrum $\beta$-lactamase (ESBL)-producing Escherichia coli strains isolated from urinary tract infections
}

\author{
Ahmad FarajzadehSheikh ${ }^{1,2}$, Hojat Veisi ${ }^{2,3^{*}}$, Mojtaba Shahin ${ }^{1,2}$, Muhammad Getso ${ }^{4}$ and Abbas Farahani ${ }^{5}$
}

\begin{abstract}
Background: As an opportunistic pathogen, Escherichia coli (E. coli) is widely recognized as the main cause of nosocomial infections as well as some disorders especially those associated with urinary tract infections (UTIs). This study, therefore, sets out to determine the extent of antibiotic resistance to quinolones and to measure the frequency of anr genes (A, B, and S) within extended-spectrum beta-lactamase (ESBL) and non-ESBL-producing strains of E. coli isolated from UTI-diagnosed patients as well as to investigate their antimicrobial susceptibility patterns for some selected antibiotics in southwest Iran.

Methods: Two hundred E. coli strains were isolated from UTI-diagnosed patients, hospitalized in nine different wards of Ahvaz Golestan Hospital between November 2015 and March 2016. The isolates were confirmed through well-practiced phenotypical methods. Moreover, the antimicrobial susceptibility test was successfully performed using a disk diffusion method. ESBL production among the isolates was screened by double disk synergism test (DDST), and the gnr genes were identified using a multiplex PCR.

Results: Out of the 200 samples collected, 167 isolates were confirmed to be E. coli strains. Maximum and minimum resistance were reported against nalidixic acid and chloramphenicol with $65.3 \%$ and $17.4 \%$, respectively. Most of the isolates were resistant to all three types of quinolones studied in this research. Using multiplex PCR, the qnr genes were found in 100 (59.88\%) strains (qnr $\mathrm{A}=10$, qnrB $=21$, qnrS $=41$, qnrB-S $=21$, qnrB- $\mathrm{A}=1$, qnrA-S $=3$, gnrA-B-S $=3$ ), $58 \%$ of which was found among ESBL-producing isolates.

Conclusions: Resistance to quinolones antibiotics was highest among ESBL-producing isolates harboring, especially qnrS among other determinants of the gnr gene. There is a need for sensitive antibiotic stewardship especially in hospitals of Ahvaz, Khuzestan province. Further research is needed to ascertain the gravity of quinolones resistance in Iran and to quickly act against its spread among other nosocomial pathogens.
\end{abstract}

Keywords: E. coli, UTIs, Qnr, ESBL

\footnotetext{
*Correspondence: hojatveisi1@gmail.com

${ }^{2}$ Department of Microbiology, School of Medicine, Ahvaz Jundishapur

University of Medical Sciences, Ahvaz, Iran

${ }^{3}$ Department of Microbiology, Arvand international Division, Ahvaz

Jundishapur University of Medical Sciences, Ahvaz, Iran

Full list of author information is available at the end of the article
}

(c) The Author(s). 2019 Open Access This article is distributed under the terms of the Creative Commons Attribution 4.0 International License (http://creativecommons.org/licenses/by/4.0/), which permits unrestricted use, distribution, and reproduction in any medium, provided you give appropriate credit to the original author(s) and the source, provide a link to the Creative Commons license, and indicate if changes were made. The Creative Commons Public Domain Dedication waiver (http://creativecommons.org/publicdomain/zero/1.0/) applies to the data made available in this article, unless otherwise stated. 


\section{Background}

As an opportunistic pathogen, Escherichia coli (E. coli) is regarded as the main cause of nosocomial infections, especially such medical disorders as UTIs (urinary tract infections), sepsis, aspiratory infections, and meningitis among neonates. The outbreak of plasmid-mediated quinolone resistance (PMQR) has steadily been increasing in recent years, leading to a decline in optimal therapeutic options [1].

Quinolones are a group of broad-spectrum antimicrobial agents that are helpful in the treatment of several infections caused by gram-negative bacteria, especially $E$. coli. However, over the past few years, the gram-negative bacteria have increasingly turned to be resistant to quinolones in Iran $[1,2]$.

Quinolones are a group of wide-spectrum antimicrobials that are often used to treat E. coli infections. Several genes and systems involved in quinolone resistance Enterobacteriaceae isolates. Quinolone resistance gene (qnr), a member of PMQR determinants, was initially discovered in a strain of Klebsiella pneumoniae (K. pneumonia).

The first member of this family $\left(q n r_{\mathrm{s}}\right)$ is $q n r \mathrm{~A}$ that was discovered in the USA in 1998 [1, 3]. Qnr proteins are responsible for protecting the target enzymes including topoisomerase IV and DNA gyrase against quinolones such as ciprofloxacin and norfloxacin [4].

Qnr genes such as $q n r \mathrm{~A}, q n r \mathrm{~B}$, and $q n r \mathrm{~S}$ are three types of the main classes of $q n r$ determinants which have been identified in several members of Enterobacteriaceae family such as E. coli and K. pneumonia $[3,5,6]$.

Over the past few years, researchers have discovered some other classes of the gene namely $q n r C$ and $q n r \mathrm{D}$ $[6,7]$. The $q n r$ gene product is composed of pentapeptide repeat proteins which protect the strains against the effects of quinolone antibiotics. Moreover, $q n r$ gene products may result in 8 to a 32-fold rise in minimum inhibitory concentration (MIC) against these groups of antibiotics, enabling these types of proteins to reduce the ciprofloxacin activity. Structural modification in its structure may follow antibiotic pressure, leading to resistance to quinolones thereafter [8].

The extent of quinolone resistance in clinical isolates such as $E$. coli is unexpectedly high in Iran, especially in those strains that produce ESBLs [1]. Moreover, ESBLs genes have often been reported as being co-associated with genes that encode PMQR (qnr, aac (6')-Ib-cr and $q e p \mathrm{~A}$.) and sometimes other families of ESBL genes (blaSHV and blaTEM) have been found located together with $q n r$ genes on a special plasmid in a pathogen isolate $[9,10]$. The $q n r$ genes are widespread all around the world, especially in hospitalized patients.

This study, therefore, is set out to determine the extent of antibiotic resistance to quinolones and to measure the frequency of $q n r$ genes $(\mathrm{A}, \mathrm{B}$, and $\mathrm{S}$ ) within
non-ESBL and ESBL-producing strains of E. coli isolated from UTI-diagnosed patients as well as to investigate their antimicrobial susceptibility patterns for some selected antibiotics in southwest Iran.

\section{Materials and methods}

Patients and bacterial strains

Two hundred bacterial isolates from the urine of UTI-diagnosed patients were collected from the clinical laboratory of Golestan Hospital (affiliated to the Jundishapur Medical University of Ahvaz, Khuzestan province, Iran). The isolates were from both male and female outpatients and inpatients diagnosed with UTI who presented at different wards of Golestan Hospital such as urology, nephrology, ICU, internal, pediatric, transplant, psychology, and outpatient department (OPD) from November 2015 to March 2016. The isolates were then transported to the Department of Medical Microbiology in the Jundishapur University of Ahvaz for further processing and analysis as outlined below. The cases were divided into nine age groups $(1,0-10 ; 2,11-20 ; 3$, 21-30; 4, 31-40; 5, 41-50; 6, 51-60; 7, 61-70; 8, 71-80; $9,81-90)$. Out of the 200 clinical bacterial isolates collected from hospital laboratory, 167 isolates were confirmed as bacilli with the ability to grow in MacConkey agar and fermented lactose (overnight), tested negative with Gram's staining, oxidase test, triple sugar iron agar, $\mathrm{SH}_{2}$-indol-motility, Voges-Proskauer, urease test, and citrate utilization test but positive with motility, indole, and Methyl Red tests [11]. All 167 isolates were confirmed using the API20E identification kit (bioMerieux SA, Marcy l'Etoile, France) to E. coli [12].

\section{Antimicrobial susceptibility pattern}

The antimicrobial susceptibility test was performed using the disk diffusion method, in Muller-Hinton agar (MHA, Merck, Germany) plate. The antibiotics disc tested based on the minimal growth inhibitory zone diameter were nalidixic acid $(\mathrm{NA}=30 \mu \mathrm{g})$, ciprofloxacin (Cip $=5 \mu \mathrm{g})$, ofloxacin $(\mathrm{OF}=5 \mu \mathrm{g})$, chloramphenicol (CL $=30 \mu \mathrm{g})$, cefotaxime $(30 \mu \mathrm{g})$, ceftazidime $(30 \mu \mathrm{g})$ and aztreonam $(\mathrm{AZT}=30 \mu \mathrm{g})$ (Mast Group, Bootle, UK) [13]. The results were interpreted as resistant, intermediate or sensitive, in accordance with the guidelines of the CLSI (2015) and the manufacturer protocols [4]. The strains used for quality control were E. coli ATCC 25922 and Enterococcus fecalis ATCC 29212.

\section{ESBLs screening test}

A DDST method was used to screen for ESBLs production among the tested isolates. To all isolates that were identified as resistant strains to ceftazidime or cefotaxime (on MHA media), a double disk (containing clavulanic acid and ceftazidime or clavulanic acid and 
cefotaxime) was placed (near the single disk). If there was $\geq 5 \mathrm{~mm}$ extra zone diameter difference between the single disk and the double disk, after overnight incubation, the test strain was reported as ESBL positive. $K$. pneumoniae ATCC 700603 and E. coli ATCC 25922 were used as positive and negative control strains respectively, in accordance with CLSI guidelines.

Detecting qnr (A, B, and S) genes by multiplex PCR technique At first $E$. coli isolates were cultivated in Luria-Bertani broth at $37^{\circ} \mathrm{C}$ overnight. At the second step, four to five colonies of the isolates were transferred to a microtube containing $1.5 \mathrm{ml}$ DW (water), and finally, the bacterial DNA was extracted for molecular analysis [3] via boiling method. Based on the sequence arrangements of the target genes, six primers were used [14] to amplify the internal fragments of $580 \mathrm{bp}, 264 \mathrm{bp}$, and $428 \mathrm{bp}$ for $q n r \mathrm{~A}, \mathrm{~B}$, and $\mathrm{S}$ genes, respectively. Nucleotide sequence primers used for detection of $q n r(\mathrm{~A}, \mathrm{~B}$, and $\mathrm{S}$ ) genes by the multiplex PCR method are presented in Table 1 . The multiplex PCR was performed in a $50 \mu$ l reaction mixture, containing $2 \mu \mathrm{l}$ of total DNA, $6 \mu \mathrm{l}$ of the primers ( $1 \mu \mathrm{l}$ for each), $22 \mu \mathrm{l}$ of the DW, and $20 \mu \mathrm{l}$ of the master kit (Sinaclon, made in Iran). Target fragments were amplified using a thermal cycler (Eppendorf, Germany) as follows: initial denaturation at $94{ }^{\circ} \mathrm{C}$ for 4 min, 30 cycles of amplification consisting of denaturation at $94{ }^{\circ} \mathrm{C}$ for $30 \mathrm{~s}$, annealing at $53{ }^{\circ} \mathrm{C}$ for $45 \mathrm{~s}$, extension at $72{ }^{\circ} \mathrm{C}$ for $30 \mathrm{~s}$, and a final extension stage at $72{ }^{\circ} \mathrm{C}$ for $6 \mathrm{~min}$. The electrophoresis of the PCR products was performed on $2 \%$ agarose gel stained with ethidium bromide $(0.5 \mu \mathrm{g} / \mathrm{ml})$ as follows: $5 \mu \mathrm{l}$ of PCR product was mixed with $1 \mu \mathrm{l}$ of loading buffer, and then run at $110 \mathrm{~V}$ for $50 \mathrm{~min}$ in $1 \times$ TBE [tris 54 $\mathrm{g}(\mathrm{pH} \pm=8-8.3), 27.5 \mathrm{~g}$ boric acid, $20 \mathrm{ml}$ EDTA] solution. All positive controls for qnrA, B, and $\mathrm{S}$ were obtained from Pastor Institute, Iran. The products of these genes (qnrA, B, and S) were sequenced (Macrogen Company, Korea) and confirmed in the NCBI database (http://blast.ncbi.nlm.nih.gov/).

Table 1 Primers for polymerase chain reaction of gnr (A, B, and S) genes

\begin{tabular}{llll}
\hline Primers $^{\mathrm{a}}$ & Nucleotide sequences & Size & Reference \\
\hline anrA-F & 5-AGAGGATTCTCACGCCAGG-3 & $580 \mathrm{bp}$ & {$[14]$} \\
qnrA-R & 5-TGCCAGGCACAGATCTTGAC-3 & & \\
qnrB-F & 5-GGMATHGAAATTCGCCACTG-3 & 264 bp & \\
qnrB-R & 5-TTTGCYGYYCGCCAGTCGAA-3 & & \\
qnrS-F & 5-GCAAGTTCATTGAACAGGGT-3 & 428 bp & \\
qnrS-R & 5-TCTAAACCGTCGAGTTCGGCG-3 & & \\
\hline
\end{tabular}

${ }^{\mathrm{a}} \mathrm{F}$ sense primer, $R$ antisense primer

\section{Statistical analysis}

The statistical analysis was done using SPSS software (IBM, Chicago, IL, USA) version 20. For the purposes of this study, Fisher's test and the non-parametric chi-squared test were performed and $P$ value $<0.05$ was considered statistically significant.

\section{Results}

Out of the 200 urinary bacterial isolates collected from the hospital, a total of 167 isolates was confirmed as $E$. coli. Most of the isolates were gathered from OPD (59\%) (Fig. 1). The total cases included $40.72 \%$ inpatients and $59.21 \%$ outpatients; $68.26 \%$ of whom were females and $31.74 \%$ were males. The majority (39\%) of these patients belonged to the third (21-30 year) and forth (31-40 year) age groups. The results of the antibacterial susceptibility test revealed that most isolates were resistant to NA (65.3\%), while least resistance was demonstrated against CL (17.4\%) (Table 2). Resistance to NA (37.61\%) and Cip (44.28\%) was mostly seen among the third and the fourth (21-40 age) age groups. The highest percentage of resistance to NA $(70.83 \%, 17 / 24)$ and Cip $(66.66 \%, 16 / 24)$ was seen among the isolates collected via the urology ward. Interestingly, most of the isolates were resistant to all the three types of quinolone antibiotics tested upon (Table 2). The results of ESBLs screening revealed that $64.07 \%(107 / 167)$ of the tested E. coli strains were ESBL positive, out of which $65.91 \%$ were isolated from the outpatients and the rest from the inpatients. The majorities of ESBL- producing bacteria were isolated from females (66.35\%) and were also gathered via OPD, whereas the least proportion of the isolates (1.19\%) was collected from psychology wards. The qnr genes were successfully amplified by multiplex PCR technique (Fig. 2), and the results of this technique revealed that $100 / 167$ (59.88\%) of the isolates harbored the $q n r$ genes with the following distributions: qnrA, $n=10$; qnrB, $n=21$; qnrS, $n=41$; qnrB-S, $\mathrm{n}=21$; qnrB-A, $n=1$; qnrA-S, $n=3$; qnrA-B-S, $n=3$ (Table 3 ).

Fifty-eight percent $(58 / 100)$ of the $q n r$ genes-carrying isolates were ESBL producers (Table 3). Among the ESBL and qnr positive strains, 9/58 (15.5\%) were sensitive to all quinolone antibiotics (Fig. 3). The study also revealed that $65.85 \%$ of the 41 isolates carrying only $q n r S$ gene were resistant to all the three types of quinolone antibiotics (NA, OF, Cip), suggesting that qnrS gene seems to result in more resistance to quinolones than $q n r \mathrm{~B}$ and $q n r \mathrm{~A}$ (Table 4). A significant correlation $\left(P_{\text {value }}<0.05\right)$ was observed between ciprofloxacin and ofloxacin among the strains harboring qurS genes (Table 4). Moreover, in cases where a combination of $q n r S$ and B was detected, the resistance to quinolones escalated to over $95 \%$ (Table 4). The relationship between ESBLs production, presence of $q n r$ genes, and the 


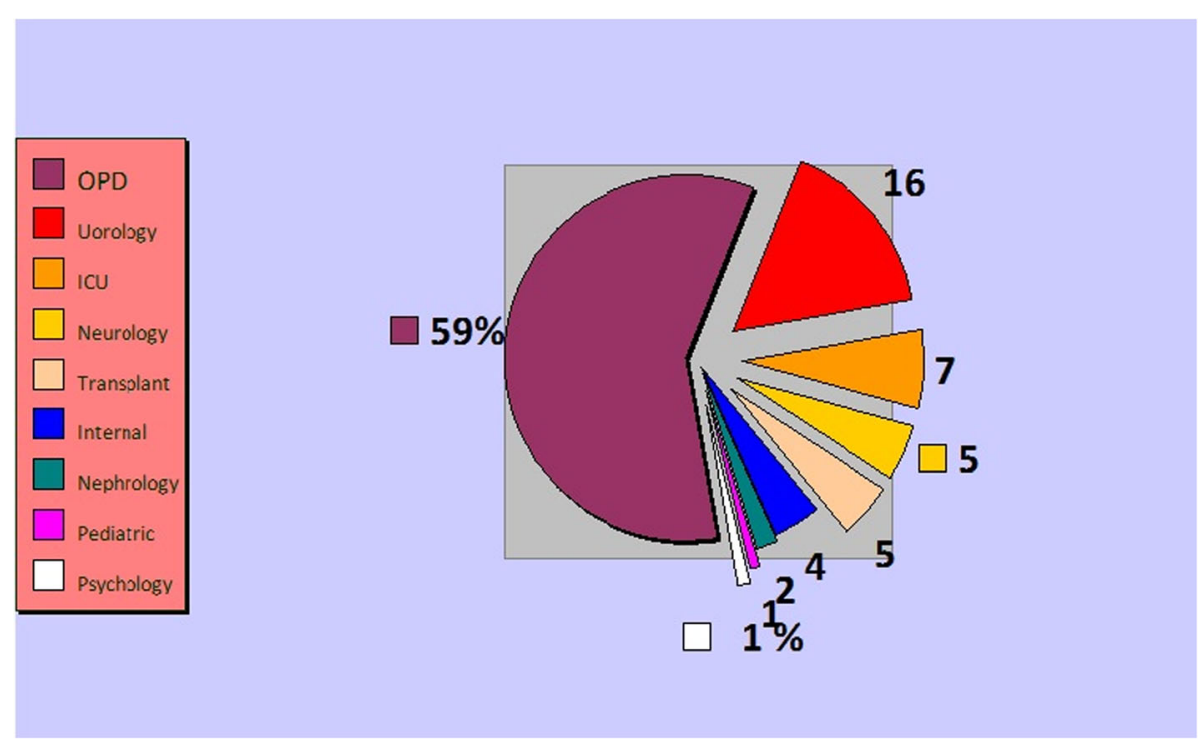

Fig. 1 The percentage of anr genes among Escherichia coli isolates in nine wards. ICU, intensive care unit; OPD, outpatient department

quinolone resistance patterns among the tested strains is shown in Fig. 3.

\section{Discussion}

Over the last decades, E. coli has been recognized as one of the leading causes of nosocomial infections in the world. In principle, some genes located on the especial plasmids in such strains are regarded as being responsible for such problems $[15,16]$. By developing some proteins, the genes (qnrs, ESBLs) build up resistance to antibiotics [17]. Though $q n r$ genes and ESBLs are the most significantly resistant agents (against $\beta$-lactam and quinolone drugs), recently, the rate of resistance to other antibiotics has sharply risen $[1,17]$. In our study, the majority (68.26\%) of the UTI-diagnosed patients were women. This might be related to the anatomical position of women's urethral tract closer to the anal canal; in addition, most of these patients belong to the third and fourth age groups (aged between 21and 40 years)-the most sexually active age group. Thus, it could be

Table 2 Antimicrobial-susceptibility for Escherichia coli isolates

\begin{tabular}{llll}
\hline Antibiotics (AB) & \multicolumn{3}{l}{ Susceptibility; no. (\%) of isolates } \\
\cline { 2 - 4 } & Susceptible (S) & Intermediate (I) & Resistant (R) \\
\hline Aztreonam (AZT) & $76(45.5)$ & $22(13.2)$ & $69(41.3)$ \\
Cefotaxime (CTX) & $57(34.1)$ & $8(4.8)$ & $102(61.1)$ \\
Ceftazidime (CAZ) & $66(39.5)$ & $16(9.6)$ & $85(50.9)$ \\
Ciprofloxacin (CIP) & $67(40.1)$ & $13(7.8)$ & $87(52.1)$ \\
Chloramphenicol (CL) & $110(65.9)$ & $28(16.8)$ & $29(17.4)$ \\
Nalidixic acid (NA) & $53(31.7)$ & $5(3)$ & $109(65.3)$ \\
Ofloxacin (OF) & $75(44.9)$ & $4(2.4)$ & $88(52.7)$ \\
\hline
\end{tabular}

concluded that sex and age are two important factors regarding the prevalence of UTIs, as reported by Rahn [18]. In the current study, the isolates showed the highest resistance to NA (65.3\%) and least resistance to CL (17.4\%). Therefore, it appears that the use of nalidixic acid for the treatment of E. coli associated with UTIs in this center might be ineffective. However, since chloramphenicol is not routinely used clinically, aztreonam can still be a drug of choice for treating UTIs. Furthermore,

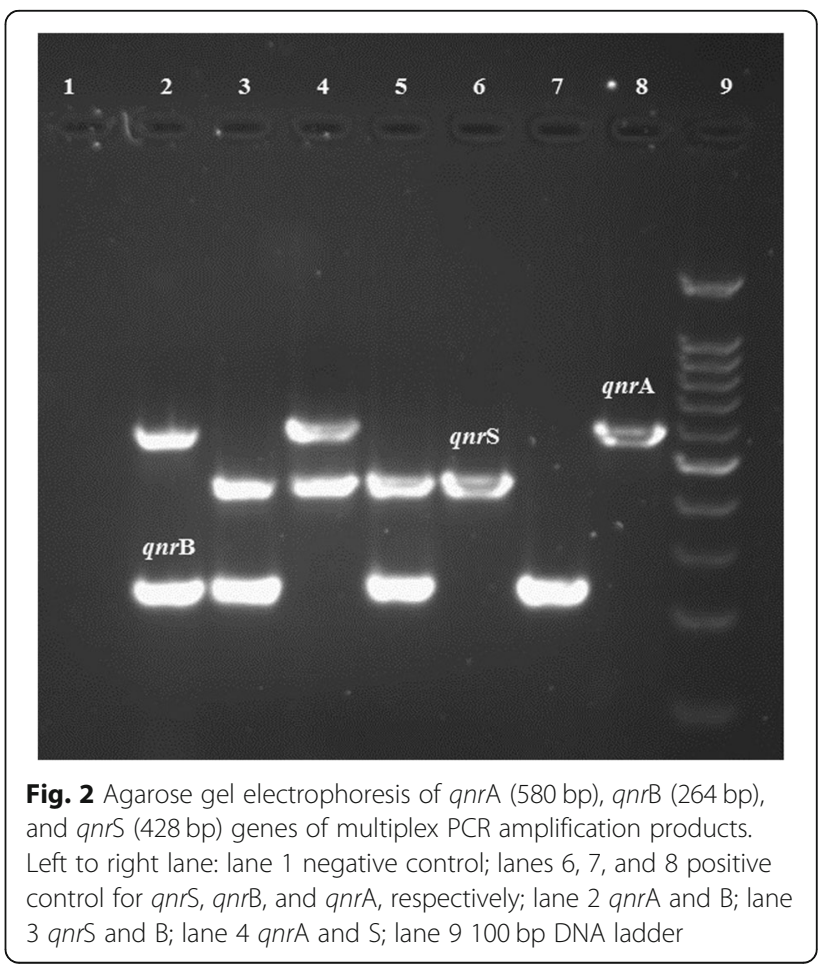


Table 3 Frequency of different qnr genes, among ESBL pos, ESBL neg, and outpatients and inpatients

\begin{tabular}{|c|c|c|c|c|}
\hline \multirow{2}{*}{$\begin{array}{l}\text { Qnr A,B, } \\
\text { and S }\end{array}$} & \multicolumn{2}{|l|}{ ESBL } & \multicolumn{2}{|l|}{ Patients } \\
\hline & Positive & Negative & Outpatients & Inpatients \\
\hline QnrA & 6 & 4 & 8 & 2 \\
\hline QnrB & 8 & 13 & 12 & 9 \\
\hline QnrS & 30 & 11 & 22 & 19 \\
\hline QnrS-B & 12 & 9 & 13 & 8 \\
\hline QnrA-S & 0 & 3 & 2 & 1 \\
\hline QnrA-B & 0 & 1 & 1 & 0 \\
\hline QnrA-B-S & 2 & 1 & 1 & 2 \\
\hline \multirow[t]{2}{*}{ Total isolates } & 58 & 42 & 59 & 41 \\
\hline & 100 & & 100 & \\
\hline
\end{tabular}

Abbreviations: ESBL pos ESBL positive, ESBL neg ESBL negative

the low resistance to chloramphenicol found in the study could be related to its low usage in routine treatments for UTIs.

Interestingly, most of the isolates were resistant to all the quinolone-containing antibiotics, (Table 2). This could be due to the reckless and inappropriate usage of the drugs [19]. Unfortunately, the rate of quinolone resistance in southwest Iran (Ahvaz) is significantly higher than other parts of Iran as reported by Pakzad et al. and even higher than what is found in other parts of the world [20]. According to the findings of this study, $64.07 \%$ of the isolates were ESBL producers. A lower rate of ESBL-producing strains has been reported in Japan and the USA [21, 22]. In Korea, it was reported to be $17.7 \%$ and $84 \%$ of ESBL-positive E. coli strains in 2003 and 2009, separately [15, 17]. Mood et al. reported that $42.5 \%$ of the E. coli isolates they studied were ESBL producers and this is lower than the finding of our study. The frequency of ESBL-producing E. coli was,
Table 4 Percentage of resisting isolates to nalidixic acid, ofloxacin, and ciprofloxacin, among strains which have harbored just one type of anr genes and/or anr $\mathrm{S}$ and $\mathrm{B}$

\begin{tabular}{lllll}
\hline Antibiotics & anr B & qnr A & anr S & qnr S-B \\
& 21 (no) & 10 (no) & 41 (no) & 21 (no) \\
\hline Nalidixic acid (\%) & 33.33 & 60.00 & 73.17 & 100 \\
Ofloxacin (\%) & 28.57 & 50.00 & $70.73^{*}$ & 95.23 \\
Ciprofloxacin (\%) & 28.57 & 50.00 & $68.29^{*}$ & 95.23 \\
NA, OF, and CIP (\%) & 28.57 & 50.00 & 65.85 & 95.23 \\
\hline
\end{tabular}

Abbreviations: $R$ resistant, no number

${ }^{*} P$ value $<0.05$

therefore, higher in our study (except for the Korean study in 2009) than what has been reported from other countries and other Iranian metropolises [19]. Arbitrarily speaking, this high rate of ESBLs isolates in Iran and the lower frequency in some other countries could be attributed to several factors including but not limited to drug abuse pattern [23]. Studies have been conducted for $q n r$ genes on $E$. coli strains in some Asian countries such as Korea (qnrB 5.6\%), Japan (qnrA 6.5\%), China (qnrA 8\%) and Iran (qnrA 6\%, qnrB 2.66\%). Several pieces of research have been carried out in Europe (UK and Germany) and the USA on qnr genes among isolates of $E$. coli and other members of Enterobacteriaceae, but only Robicsec et al. reported qnrA (4\%) in the USA [24, 25]. Moreover, the total percentage of E. coli isolates harboring $q n r$ genes (59.88\%) reported in this study, as shown in Table 3, is significantly higher in number and diversity than those reported in Europe, Asia, and the USA [23, 26, 27]. It seems there is a high frequency of transconjugation or transformation mechanisms of the genes occurring in southwestern Iran, and this could be attributed to the hot and humid climate [23] of southwest Iran. Fifty-eight percent of the strains harboring $q n r$ genes were also ESBL producers (Table 3)

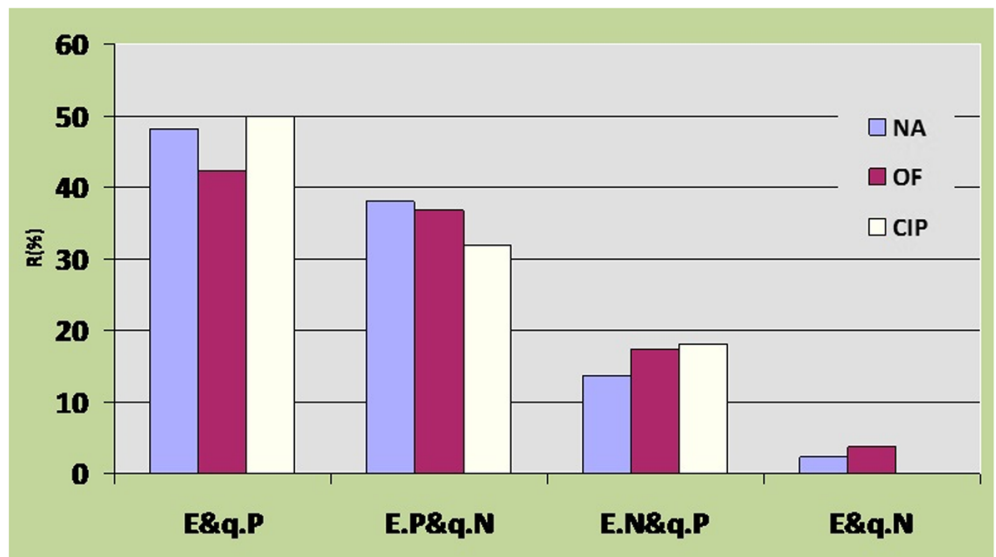

Fig. 3 Quinolone resistance pattern of ESBL-producing Escherichia coli isolates harboring qnr genes. Left to right: E\&q.P, ESBL and qnr positive; E.P\&q.N, ESBL positive and qnr negative; E.N\&q.P, ESBL negative and qnr positive; E\&q.N, ESBL and qnr negative 
and showed the highest level of resistance to quinolones (ESBL and qnr positive strains, as shown in Fig. 3). Moreover, the lowest level of resistance was seen among $q n r$ and ESBL negative strains (Fig. 3). Contrary to our expectations, seven (4.19\%) qnr and ESBL-negative isolates were resistant to all quinolones mentioned, which might be due to other different defensive mechanisms. On the other hand, nine (5.38\%) qnr and ESBL-positive isolates were absolutely sensitive to all quinolones, most probably the resistance genes in those strains were silent $[23,28,29]$. Out of the total isolates harboring $q n r$ genes, $10 \%(10 / 100)$ isolates contained qnrA, $21 \%$ $(21 / 100)$ isolates contained qnrB, $41 \%(41 / 100)$ isolates contained $q n r S$, and $21 \%(21 / 100), 1 \%(1 / 100)$, $3 \%(3 / 100)$, and $3 \%(3 / 100)$ isolates contained a mix of $q n r \mathrm{~S}-\mathrm{B}, q n r \mathrm{~B}-\mathrm{A}, q n r \mathrm{~A}-\mathrm{S}, q n r \mathrm{~A}-\mathrm{B}-\mathrm{S}$, respectively.

The qnrS gene seems to play a more significant role than qurA and $q n r \mathrm{~B}$ with regard to quinolones resistance since $65.85 \%$ (27/41) of the isolates harboring the qurS gene were resistant to all quinolones (Table 4). As shown in Table 4, the combination of qnrS and B detected in some strain have increased the level of resistance to quinolone-containing antibiotics nearly to $100 \%$ (20 of 21 ), suggesting that the synergistic effects resulting from the combination of qurS with $q n r \mathrm{~B}$ in a strain may increase their defensive positions. Also, a significant correlation $(P$ value $<0.05)$ was reported between $q n r S$ gene and resistance to Cip and OF (Table 4). Attaining complete cure from UTIs caused by E. coli is highly challenging, and the presence of $q u r$ genes and ESBLs production are said to be most responsible. However, some other factors such as the overexpression of efflux pump or declined intracellular concentration and mutations (in topoisomerase IV and DNA gyrase enzymes) could also be equally effective in this regard [12, 30, 31]. On the other hand, quinolones are the most prescribed antibiotics for UTI therapy in Iran. Today, one of the most important concerns is the risk of treatment failure among Iranian patients, especially those diagnosed with UTIs [20,32]. To the best of our knowledge, this is the first study to investigate the presence of $q n r$ genes (A, B, and $S$ ) in both ESBL-producing and non-ESBLs strains of $E$. coli isolated from patients diagnosed with UTIs and their resistance patterns to quinolones antibiotics in southwest Iran. Finally, the major limitations were small sample size, study of only seven drugs in terms of antimicrobial susceptibility, and single center-based design of this study.

\section{Conclusion}

The frequency of qur genes among clinical isolates of $E$. coli demonstrated in this study is higher than the usually reported frequency from other provinces of Iran. Resistance to quinolones antibiotics was highest among
ESBL-producing isolates, especially those harboring $q n r S$ among other determinants of $q n r$ gene. There is a need for sensitive antibiotic stewardship especially in the health facilities of Ahvaz, Khuzestan province. Further research, with a wider scope, is needed to ascertain the gravity of quinolones resistance in Iran and to quickly act against its spread among other nosocomial pathogens.

\section{Abbreviations \\ AZT: Aztreonam; CAZ: Ceftazidime; CIP: Ciprofloxacin; CL: Chloramphenicol; CTX: Cefotaxime; DDST: Double disk synergism test; ESBL: Extended-spectrum $\beta$-lactamase; ICU: Intensive care unit; MIC: Minimum inhibitory concentration; NA: Nalidixic acid; No: Number; OF: Ofloxacin; OPD: Outpatient department; PMQR: Plasmid-mediated quinolone resistance; qnr: Quinolone resistance gene; R: Resistant; UTIs: Urinary tract infections}

\section{Acknowledgements}

We gratefully acknowledge the Vice-Chancellor for Research and Technology, Ahvaz Jundishapur University of Medical Sciences, for financial support of this study as a Medical Microbiology Master thesis of Hojat Veisi, Ahvaz Jundishapur University of Medical Sciences, Ahvaz, Iran (Grant No.B-9465).

\section{Funding}

This study was funded in part by research grants from the Ahvaz

Jundishapur University of Medical Sciences, Ahvaz, Iran, who had no role in the data collection, analysis, interpretation, and conclusion made herewith.

\section{Availability of data and materials}

All data associated with this manuscript is inclusive in this paper.

\section{Authors' contributions}

AFK and HV conceived the project and designed the experiments. HV, MS, and AF designed and collected samples. HV, AFK, MS, MG, and AF analyzed the data. AFK and $\mathrm{HV}$ supervised the collection of the samples. HV, AFK, MS, MG, and AF wrote the manuscript. All authors reviewed and approved the manuscript.

\section{Ethics approval and consent to participate}

This work was approved (Code: IR.AJUMS.REC. B-9465) by the research ethics committee of the Ahvaz Jundishapur University of Medical Sciences, Iran. In this way, all patients gave their written informed consent for participation.

Consent for publication

Not applicable.

\section{Competing interests}

The authors declare that they have no competing interest.

\section{Publisher's Note}

Springer Nature remains neutral with regard to jurisdictional claims in published maps and institutional affiliations.

\section{Author details \\ ${ }^{1}$ Infectious and Tropical Diseases Research Center, Health Research Institute, Ahvaz Jundishapur University of Medical Sciences, Ahvaz, Iran. ${ }^{2}$ Department of Microbiology, School of Medicine, Ahvaz Jundishapur University of Medical Sciences, Ahvaz, Iran. ${ }^{3}$ Department of Microbiology, Arvand international Division, Ahvaz Jundishapur University of Medical Sciences, Ahvaz, Iran. ${ }^{4}$ Department of Medical Microbiology and Parasitology, College of Health Sciences, Bayero University, PMB, Kano 3011, Nigeria. ${ }^{5}$ Infectious and Tropical Diseases Research Center, Hormozgan Health Institute, Hormozgan University of Medical Sciences, Bandar Abbas, Iran.}

Received: 16 November 2018 Accepted: 20 February 2019 Published online: 04 March 2019

\section{References}

1. Jiang X, Yu T, Wu N, Meng H, Shi L. Detection of qnr, aac (6')-lb-cr and qepA genes in Escherichia coli isolated from cooked meat products in Henan, China. Int J Food Microbiol. 2014;187:22-5. 
2. Rodríguez-Martínez JM, Cano ME, Velasco C, Martínez-Martínez L, Pascual Á. Plasmid-mediated quinolone resistance: an update. J Infect Chemother. 2011;17(2):149-82.

3. Jiang Y, Zhou Z, Qian Y, Wei Z, Yu Y, Hu S, et al. Plasmid-mediated quinolone resistance determinants qnr and aac (6')-Ib-cr in extendedspectrum beta-lactamase-producing Escherichia coli and Klebsiella pneumoniae in China. J Antimicrob Chemother. 2008;61(5):1003-6.

4. Briales A, Rodriguez-Martinez JM, Velasco C, de Alba PD, Rodriguez-Bano J, Martinez-Martinez $L$, et al. Prevalence of plasmid-mediated quinolone resistance determinants anr and aac (6')--lb-cr in Escherichia coli and Klebsiella pneumoniae producing extended-spectrum beta-lactamases in Spain. Int J Antimicrob Agents. 2012;39(5):431-4.

5. Hopkins KL, Davies RH, Threlfall EJ. Mechanisms of quinolone resistance in Escherichia coli and Salmonella: recent developments. Int J Antimicrob Agents. 2005;25(5):358-73.

6. Yue L, Jiang HX, Liao XP, Liu JH, Li SJ, Chen XY, et al. Prevalence of plasmidmediated quinolone resistance anr genes in poultry and swine clinical isolates of Escherichia coli. Vet Microbiol. 2008;132(3-4):414-20.

7. Ruiz E, Saenz Y, Zarazaga M, Rocha-Gracia R, Martinez-Martinez L, Arlet G, et al. gnr, aac (6')-Ib-cr and qepA genes in Escherichia coli and Klebsiella spp:: genetic environments and plasmid and chromosomal location. J Antimicrob Chemother. 2012;67(4):886-97.

8. Li X-Z. Quinolone resistance in bacteria: emphasis on plasmid-mediated mechanisms. Int J Antimicrob Agents. 2005;25(6):453-63.

9. Jeong J-Y, Yoon HJ, Kim ES, Lee Y, Choi S-H, Kim NJ, et al. Detection of anr in clinical isolates of Escherichia coli from Korea. Antimicrob Agents Chemother. 2005;49(6):2522-4.

10. Wang A, Yang $Y, L u Q$, Wang $Y$, Chen $Y$, Deng $L$, et al. Presence of gnr gene in Escherichia coli and Klebsiella pneumoniae resistant to ciprofloxacin isolated from pediatric patients in China. BMC Infect Dis. 2008;8(1):68,

11. Wayne P. Clinical and laboratory standards institute. Performance standards for antimicrobial susceptibility testing 2016.

12. Mohajeri P, Darfarin G, Farahani A. Genotyping of ESBL producing Uropathogenic Escherichia coli in west of Iran. Int J Microbiol. 2014;2014. https:/www.hindawi.com/journals/ijmicro/2014/276941/.

13. Pereira AS, Andrade SS, Monteiro J, Sader HS, Pignatari AC, Gales AC Evaluation of the susceptibility profiles, genetic similarity and presence of anr gene in Escherichia coli resistant to ciprofloxacin isolated in Brazilian hospitals. Braz J Infect Dis. 2007;11(1):40-3.

14. Cattoir V, Poirel L, Rotimi V, Soussy CJ, Nordmann P. Multiplex PCR for detection of plasmid-mediated quinolone resistance qnr genes in ESBLproducing enterobacterial isolates. J Antimicrob Chemother. 2007;60(2):394-7.

15. Park JH, Lee SH, Jeong SH, Kim BN, Kim KB, Yoon JD, et al. Characterization and prevalence of Escherichia coli and Klebsiella pneumoniae isolates producing an extended-spectrum beta-lactamase from Korean hospitals. Korean J Lab Med. 2003;23(1):18-24.

16. Jones RN, Pfaller MA, Doern GV, Erwin ME, Hollis RJ, Group CS. Antimicrobial activity and spectrum investigation of eight broad-spectrum $\beta$-lactam drugs: a 1997 surveillance trial in 102 medical centers in the United States. Diagn Microbiol Infect Dis. 1998;30(3):215-28.

17. Park Y, Kang H-K, Bae IK, Kim J, Kim J-S, Uh Y, et al. Prevalence of the extended-spectrum $\beta$-lactamase and gnr genes in clinical isolates of Escherichia coli. Korean J Lab Med. 2009;29(3):218-23.

18. Rahn DD. Urinary tract infections: contemporary management. Urol Nurs. 2008;28(5):333-41 quiz 42.

19. Mood EH, Meshkat Z, Izadi N, Rezaei M, Jamehdar SA, Nasab MN. Prevalence of quinolone resistance genes among extended-spectrum Blactamase-producing Escherichia coli in Mashhad, Iran. Jundishapur J Microbiol. 2015;8(12).

20. Pakzad I, Ghafourian S, Taherikalani M. Qnr prevalence in extendedspectrum beta-lactamases (ESBLs) and none-ESBLs producing Escherichia coli isolated from urinary tract infections in central of Iran. Iran J Basic Med Sci. 2011;14(5):458

21. Munshi M, Haider K, Rahaman M, Sack D, Ahmed Z, Morshed M. Plasmidmediated resistance to nalidixic acid in Shigella dysenteriae type 1. Lancet. 1987:330(8556):419-21.

22. Martínez-Martínez L, Pascual A, Jacoby GA. Quinolone resistance from a transferable plasmid. Lancet. 1998;351(9105):797-9.

23. Corkill JE, Anson JJ, Hart CA. High prevalence of the plasmid-mediated quinolone resistance determinant anrA in multidrug-resistant
Enterobacteriaceae from blood cultures in Liverpool, UK. J Antimicrob Chemother. 2005;56(6):1115-7.

24. Poirel L, Leviandier C, Nordmann P. Prevalence and genetic analysis of plasmid-mediated quinolone resistance determinants QnrA and QnrS in Enterobacteriaceae isolates from a French university hospital. Antimicrob Agents Chemother. 2006;50(12):3992-7.

25. Allou N, Cambau E, Massias L, Chau F, Fantin B. Impact of low-level resistance to fluoroquinolones due to qnrA1 and gnrS1 genes or a gyrA mutation on ciprofloxacin bactericidal activity in a murine model of Escherichia coli urinary tract infection. Antimicrob Agents Chemother. 2009; 53(10):4292-7.

26. Jonas D, Biehler K, Hartung D, Spitzmüller B, Daschner FD. Plasmidmediated quinolone resistance in isolates obtained in German intensive care units. Antimicrob Agents Chemother. 2005;49(2):773-5.

27. Robicsek A, Strahilevitz J, Sahm D, Jacoby G, Hooper D. anr prevalence in ceftazidime-resistant Enterobacteriaceae isolates from the United States. Antimicrob Agents Chemother. 2006;50(8):2872-4.

28. Xue Y, Chen J, Hua Y. Resistance of strains producing extended-spectrum [beta]-lactamases and genotype distribution among Escherichia coli in China. Pak J Zool. 2012;44(2). http://zsp.com.pk/vol-44\%5B2\%5D.html, http://zsp.com.pk/pdf44/457-461\%20_23_\%20PJZ-725-11.pdf.

29. Vasilaki O, Ntokou E, Ikonomidis A, Sofianou D, Frantzidou F, Alexiou-Daniel $\mathrm{S}$, et al. Emergence of the plasmid-mediated quinolone resistance gene anrS1 in Escherichia coli isolates in Greece. Antimicrob Agents Chemother. 2008:52(8):2996-7.

30. Oktem IMA, Gulay Z, Biçmen M, Gur D, Group HPS. anrA prevalence in extended-spectrum beta-lactamase-positive Enterobacteriaceae isolates from Turkey. Jpn J Infect Dis. 2008;61(1):13.

31. Peymani A, Farivar TN, Najafipour R, Mansouri S. High prevalence of plasmid-mediated quinolone resistance determinants in Enterobacter cloacae isolated from hospitals of the Qazvin, Alborz, and Tehran provinces, Iran. Rev Soc Bras Med Trop. 2016;49(3):286-91.

32. Firoozeh F, Zibaei M, Soleimani-Asl Y. Detection of plasmid-mediated anr genes among the quinolone-resistant Escherichia coli isolates in Iran. J Infect Dev Ctries. 2014;8(07):818-22.

\section{Ready to submit your research? Choose BMC and benefit from:}

- fast, convenient online submission

- thorough peer review by experienced researchers in your field

- rapid publication on acceptance

- support for research data, including large and complex data types

- gold Open Access which fosters wider collaboration and increased citations

- maximum visibility for your research: over $100 \mathrm{M}$ website views per year

At BMC, research is always in progress.

Learn more biomedcentral.com/submissions 